\title{
AGE AND GENDER DIFFERENCES IN THE IMPACT OF PSORIASIS ON QUALITY OF LIFE
}

\author{
MADHULIKA A. GUPTA, M.D., FRCPC, AND ADITYA K. GUPTA, M.D., FRCPC
}

\begin{abstract}
Background. The impact of psoriasis upon the quality of life contributes significantly to the overall morbidity associated with the disease. An older age at onset of psoriasis and being a man have been associated previously with lower psychosocial morbidity. In order to further evaluate these potentially important mitigating factors, we examined the relation of age and gender on some aspects of psoriasis-related psychosocial morbidity.
\end{abstract}

Methods. Two hundred and fifteen consenting psoriasis patients, representing a wide range of disease severity, were studied. They included 110 men and 105 women, age range $19-87$ years (age: mean $\pm \mathrm{SD}: 48.0 \pm 15.9$ years); all endorsed a list of 30 items (by checking a "Yes" or "No") pertaining to life events related to psoriasis that they had experienced in the previous one month. The patients selfrated the severity of their psoriasis. The patients were categorized into four age groups of 18-29 years $(N=28), 30-45$ vears $(N=77), 46-65$ years $(N=76)$, and $>65$ years $(N=34)$, respectively, for the statistical analyses.

Results. No age or gender differences in the severity of psoriasis were observed. Patients of both sexes in the 18 to 29 and 30 to 45 year age groups reported more frequent $(P \leq$ 0.05) problems related to both appearance/socialization and occupation/finances, in contrast to patients in the $46-65$ and over-65-year age groups. No gender differences $(P \leq 0.05)$ were observed in the frequency of items related to appearance and socialization; however, men reported greater workrelated stresses.

Conclusion. Psoriasis has a greater impact upon the quality of life of patients in the 18 to 45 year age range and affects the socialization of both sexes equally. Men face greater work-related stresses as a result of their psoriasis.

Int J Dermatol 1995; 34:700-703

From the Department of Psychiatry University of Michigan Medical School, Ann Arbor, Michigan, the Department of Psychiatry, University of Western Ontario, London, Ontario, Canada and the Division of Dermatology, Department of Medicine, Faculty of Medicine, University of Toronto, Toronto, Ontario, Canada.

Address for correspondence: M.A. Gupta, M.D., 490 Wonderland Road South, Suite 6, London, Ontario, N6K 1L6, Canada.
The impact of psoriasis on the quality of life contributes significantly to the morbidity associated with the disease and may in turn adversely affect its course. ${ }^{1-8}$ The psychosocial morbidity associated with psoriasis has been rated by patients as the worst feature of their condition. ${ }^{3,9}$ Some studies suggest that an older age at onset of psoriasis' and patients being men are associated with lower psychosocial morbidity. Patients who were older at the time of onset of their psoriasis ${ }^{1}$ were reported to be less sensitive to the opinions of others, had a lesser tendency to anticipate rejection in social situations, were less secretive, and had fewer feelings of guilt and shame in relationship to their psoriasis. The author's' propose, that the chronologically older patients as a group, had had a more extensive life-experience than patients with early-onset psoriasis, which resulted in better emotional adjustment and mitigated the psychosocial impact of their disease. 'There was no definite delineation of the age when the patients became less vulnerable to the psychosocial impact of psoriasis. ' In another study ${ }^{9}$ a lower psychosocial morbidity among men with psoriasis was observed in contrast to women. "The authors" discuss that society tends to place a lesser importance on the appearance of men than women and that this lessens the psychosocial morbidity resulting from the effect of psoriasis upon the patient's appearance and socialization. In order to further evaluate these potentially important demographic factors that may lessen the impact of psoriasis on the quality of life, we examined the relation of age and gender to various factors that contribute towards the psychosocial morbidity associated with psoriasis. ${ }^{1-10}$

\section{Materials and Methods}

We studied 215 consecutive consenting psoriasis patients $(110$ men, 105 women; age range 19 to 87 years, age: mean $\pm \mathrm{SD} 48.0 \pm 15.9$ years $)$, representing both inpatients $(N=$ 137) and outpatients $(N=78)$ with a wide range of severity of psoriasis. This study was part of a larger study of psychosocial factors in psoriasis. A part of the data that are being presented in this paper, has been previously used in the development of the 'Psoriasis Life Stress Inventory, an instrument that measures psoriasis-related stress. ${ }^{10}$ The outpatients (41 men and 37 women; age: mean \pm SD $49.4 \pm$ 15.9 years) had less than $30 \%$ of total body surface area (TBSA) affected by psoriasis and the inpatients $(69$ men and 68 women age: mean \pm SD $47.2 \pm 16.4$ years; TBSA affected 
by psoriasis mean \pm SD: $52 \pm 23.4 \%$ ) were all patients of the Department of Dermatology, University of Michigan Hospitals, Ann Arbor. Exclusion criteria were other coexisting dermatologic or medical disorders. The outpatients were selected for recruitment from a database of patients attending the dermatology outpatient service at the University of Michigan and only the patients who had been clinically documented as having $\leq 30 \%$ of their TBSA affected by psoriasis were included in the study. For inpatients, the dermatologic assessment and psychosocial ratings were obtained within the first week of admission at the onset of treatment. The study was approved by the Institutional Review Board at the University of Michigan and a written informed consent was obtained from all participants, who were all unpaid volunteers. Demographic data such as age and sex were obtained from all patients. For the purpose of our analyses, the patients were categorized into four age groups of: 18 to 29 years $(N=28), 30$ to 45 years $(N=77)$, 46 to 65 years $(N=76)$, and $>65$ years $(N=34)$, respectively.

Items Related to the Impact of Psoriasis upon the Quality of Life: The patients endorsed a list of items by checking a "Yes" or "No" (Table 1) pertaining to life events related to psoriasis that they had experienced 1 month previously. The time scale of 1 month used in our survey is similar to that used by others ${ }^{5}$ and it is assumed that most patients will accurately recall the events that they endorse.

Dermatologic Ratings: Because the psychosocial impact of psoriasis is largely a subjective experience, we considered the patients' self-ratings of the severity of psoriasis in this study. The patients' ratings were obtained from their responses on a 10-point scale (rating of " 1 " denoted "not at all" and a rating of "10" denoted "very markedly") to the following items: "overall redness of skin rash," "overall scaling or shedding of skin," "overall thickness of psoriasis plaques," and "overall severity of psoriasis."

Statistical Analysis: A chi-square test was used to examine differences between categoric variables and two-sample t-tests and analysis of variance (ANOVA) was used to compare continuous variables. A chi-square test was used to examine the differences in the frequency of a "Yes" versus "No" response between the four age groups (P-values for all items noted in Table 1). Secondly, overall gender differences in the frequency of a "Yes" versus "No" response (independent of age) were examined for each psoriasis-related event, using a chi-square test.

\section{RESULTS}

The men (mean \pm SD age: $47.0 \pm 15.3$ years, $N=110$ ) did not differ significantly from the women (mean \pm SD age: $49.1 \pm 16.5$ years, $N=105$ ) with respect to age and severity of psoriasis ratings. Furthermore, all the ratings of the severity of psoriasis were not significantly different $(P>0.05)$ between men and women in the four age groupings. Overall, the mean \pm SD of psoriasis severity ratings on the 10-point scale discussed above were as follows: "overall redness of skin erup- tion": $5.6 \pm 3.2$; "overall scaling or shedding of skin": $4.7 \pm 3.0$; "overall thickness of psoriasis plaques": 5.1 \pm 2.7 ; and, "overall severity of psoriasis": $5.9 \pm 2.8$.

Table 1 displays the frequency of a "Yes" response to each psoriasis-related event in the four age groups and the differences in frequency with which an event was encountered in each age group. Examination of gender differences in the overall frequency of a "Yes" response, independent of age, revealed no significant sex differences (at $\mathrm{P} \leq 0.05$ ) in the frequencies of reports of the 18 items under "events related to appearance/ socialization" (Items 1 to 18 , Table 1). A marginally higher percentage $(\mathrm{P}=0.06)$ of men $(19.3 \%)$ compared to women $(9.9 \%)$ reported that people implied that their skin condition might be due to AIDS, leprosy, or a venereal disease (Item 11, Table 1). Fear that they might lose their job (Item 20, Table 1) was reported by $21.5 \%$ of men compared to $8.1 \%$ of women ( $P=$ $0.007)$ and a marginally higher percentage of men $(15.1 \%)$ compared to women $(7.1 \%)(\mathrm{P}=0.07)$ reported being criticized for taking too much time off work or school for medical appointments (Item 22, Table 1).

\section{COMMENTS}

Our findings indicate that, in general, the adverse effect of psoriasis upon the quality of life lessens in the over-45-year age group, with a further decrease in the over-65-year age group (see Table 1). The age group between 18 and 45 years experienced more frequent problems related to both appearance/socialization and occupation/finances (see Table 1). This most likely reflects the fact that in earlier adulthood, when the individual is first establishing social relationships and making contact with a wider range of people, the social stigma associated with psoriasis has a greater impact on the daily life of the individual. The social stigma becomes less important in mid-life and later, when most people are more established within a social network and are, therefore, less likely to encounter social discrimination. Similarly, the younger psoriasis patient also tends to face more occupational and/or financial stresses. The over-45-years age group on the whole is more likely to be more financially secure and therefore to experience less occupational/financial stresses related to taking time off work or to medical expenses. The financial and work-related stresses were rated as being essentially nonexistent in the over-65-years age group that most likely included many retired individuals.

Examination of sex differences revealed that psoriasis has a greater impact on occupational functioning among men than women. The men as a group were more afraid of losing their job (Item 20, Table 1) and felt greater criticism for taking time off from school or work for medical appointments (Item 22, Table 1) than women. This finding has both practical and clini- 


\begin{tabular}{|c|c|c|c|c|c|}
\hline \multirow[b]{3}{*}{$\begin{array}{l}\text { Event (Percentage of all Patients }(N=215) \\
\text { who Experienced Event } 1 \text { Month Previously }\end{array}$} & \multicolumn{4}{|c|}{$\begin{array}{l}\text { Percentage of Patients in each of } \\
\text { Following Age Groups who } \\
\text { Experienced Event } 1 \text { Month Previously }\end{array}$} & \multirow{3}{*}{$\begin{array}{l}P^{*} \text { Value of } \\
\text { Difference between } \\
\text { Percentage who } \\
\text { Experienced Event } \\
\text { in each Age Group }\end{array}$} \\
\hline & $18-29$ & $30-45$ & $46-65$ & $>65$ & \\
\hline & $\begin{array}{l}\text { Years } \\
(N=28)\end{array}$ & $\begin{array}{l}\text { Years } \\
(N=77)\end{array}$ & $\begin{array}{l}\text { Years } \\
(N=76)\end{array}$ & $\begin{array}{l}\text { Years } \\
(N=34)\end{array}$ & \\
\hline
\end{tabular}

Related to Appearance/Socialization

1. Feeling self-conscious among strangers (e.g., in a bus, elevator, store, etc.) $(53 \%)$

2. Not going to a public place (e.g., swimming pool, health club, restaurant) when you would have liked to $(50 \%)$

3. Wearing unattractive or uncomfortable clothes in order to cover certain regions of the body $(46 \%)$

4. Having to avoid sunbathing in the company of others (44\%)

5 . "People treating you as if your skin condition is contagious" $(29 \%)$

6. Avoiding social situation (e.g., partics, dances, etc.) (28\%)

7. Strangers (children or adults) making rude or insensitive remarks about your appearance $(27 \%)$

8. Feeling like an "outcast" or "social misfit" a great deal of the time $(23 \%)$

9. People making a conscious effort not to touch you (18\%)

0. Hairdresser or barber appearing reluctant to cut your hair $(15 \%)$

11. People implying that your skin condition may be due to Alds, leprosy, or a venereal disease $(15 \%)$

12. Friends making rude or insensitive remarks about your appearance $(12 \%)$

13. Your family members feeling embarassed about your skin condition $(11 \%)$

14. Family members making rude or insensitive remarks about your appearance $(10 \%)$

15. Going out of the house mainly after dark so that people would not notice how you look $(10 \%)$

16. Being rejected by girlfriend/boyfriend $(7 \%)$

17. People not wanting to be seen in your company $(4 \%)$

18. Having trouble finding proper housing $(2 \%)$

$\begin{array}{lllll}63.0 & 68.8 & 49.3 & 15.6 & <0.0001\end{array}$

$\begin{array}{lllll}67.9 & 53.2 & 54.7 & 16.1 & 0.0003\end{array}$

$\begin{array}{lllll}67.9 & 48.7 & 43.2 & 28.1 & 0.02\end{array}$

$\begin{array}{lllll}42.9 & 44.7 & 51.4 & 28.1 & 0.2\end{array}$

$\begin{array}{lllll}44.4 & 35.1 & 27.0 & 6.3 & 0.005\end{array}$

$\begin{array}{lllll}32.1 & 32.9 & 30.7 & 9.4 & 0.08\end{array}$

$\begin{array}{lllll}28.6 & 42.9 & 17.3 & 9.4 & 0.0003\end{array}$

$\begin{array}{lllll}17.9 & 30.3 & 23.9 & 6.3 & 0.049\end{array}$

$\begin{array}{lllll}28.6 & 19.5 & 18.7 & 3.1 & 0.07\end{array}$

$\begin{array}{lllll}14.3 & 19.7 & 13.7 & 6.3 & 0.3\end{array}$

$\begin{array}{lllll}28.6 & 17.1 & 11.0 & 6.3 & 0.07\end{array}$

$\begin{array}{lllll}25.0 & 18.2 & 5.4 & 0 & 0.002\end{array}$

$\begin{array}{lllll}3.6 & 15.8 & 12.2 & 6.3 & 0.3\end{array}$

$\begin{array}{lllll}10.7 & 10.5 & 14.9 & 0 & 0.2\end{array}$

$\begin{array}{lllll}14.3 & 13.0 & 9.5 & 0 & 0.2\end{array}$

$\begin{array}{lllll}15.4 & 6.1 & 7.9 & 0 & 0.2\end{array}$

$3.6 \quad 7.8$

$2.7 \quad 0$

0.2

$0 \quad 1.3$

$4.3 \quad 0$

0.3

Events Related to Occupation/Finances

19. Not enough money to pay medical bills $(22 \%)$

20. Fear that you might lose your job (15\%)

21. Loss of wages/income $(13 \%)$

22. Criticized for taking too much time off work or school for medical appointments $(11 \%)$

23. Conflicts with co-workers/classmates $(10 \%)$

24. Arguments with boss/supervisor/teacher $(10 \%)$

25 . Being refused a job you had applied for $(7 \%)$

26. Fired/laid off from your job or failed at school $(6 \%)$

27. Having to stop your studies $(5 \%)$

$42.9 \quad 25.0$

19.4

3.2

0.003

$14.3 \quad 21.1$

15.7

0.05

$32.1 \quad 26.7$

24.7

0.01

$21.4 \quad 14.5$

8.8

0.04

$17.9 \quad 15.8$

5.8

0.03

$17.9 \quad 14.5$

5.6

0.04

$10.7 \quad 10.5$

5.6

0.2

$3.6 \quad 6.6$

8.7

0.3

$7.1 \quad 9.2$

2.9

0.2

Events Related to Symptoms/Treatment

28 . Inconvenienced by the shedding of your skin $(66 \%)$

29. Feeling that you have to set aside a large part of your time to take care of your psoriasis $(51 \%)$

$\begin{array}{lllll}57.1 & 77.3 & 67.1 & 46.9 & 0.01\end{array}$

$\begin{array}{lllll}64.3 & 48.7 & 50.0 & 48.5 & 0.5\end{array}$

30. Fears of having serious side-effects from medical treatments $(31 \%)$

"Chi-square test. 
cal implications since work-related stresses and unemployment can significantly contribute towards psychosocial morbidity.

In contrast to earlier observations, we found no significant gender differences $(P \leq 0.05)$ in the impact of psoriasis on socialization (Items 1 to 18 , Table 1). This may in part reflect the fact that it is more socially acceptable for men to report that they are bothered by the effect of psoriasis upon their appearance in the 1990s than it was in the late 1970s when the earlier report was published. ${ }^{9}$ Alternately, it is possible that over the last 15 years, societal norms have shifted, so that the impact of appearance on socialization has become equally as important for both sexes. The men reported a marginally $(P=0.06)$ greater frequency of the experience that people implied that their skin condition may be due to Alns, leprosy, or a venereal disease (Item 11, Table 1). This may in part reflect the fact that the stigma of having AIDS is more commonly attributed to men, specifically homosexual men.

\section{CONCLUSIONS}

The effect of psoriasis upon the quality of life can vary greatly according to the life stage of the patient and, to some degree, the prevailing societal views and biases regarding certain disease processes. The patient with psoriasis is more likely to be stigmatized by societal biases, largely because of the high visibility of the condition. Psoriasis has a greater impact upon the quality of life of adults in the 18 to 45 year age range, a life-stage when the individual is usually expected to be the most productive, both occupationally and socially; however, although psoriasis affects the socialization of both sexes equally, men face greater work-related stresses as a result of their psoriasis. Our findings highlight the importance of assessing the psychosocial impact of psoriasis within a developmental and social context.

Acknowledgments: Gena Watteel, M.Sc., provided staristical assistance and the Department of Dermatology, University of Michigan allowed us to study their patients.

\section{REFERENCES}

1. Ginsburg $\mathrm{IH}$, Link BG. Feelings of stigmatization in patients with psoriasis. J Am Acad Dermatol 1989; 20: 53-63.

2. Fried RG, Friedman $S$, Papadis C, et al. Trivial or terrible? The psychosocial impact of psoriasis. Int J Dermatol 1995; 34:101-105.

3. Baughman RD, Sobel R. Psoriasis: a measure of severity. Arch Dermatol 1970; 101:390-393.

4. Gupta MA, Gupta AK, Kirkby S, et al. A psychocutaneous profile of psoriasis patients who are stress reactors. Gen Hosp Psychiatry 1989; 11:166-173.

5. Finlay AY, Kelly SE. Psoriasis-an index of disability. Clin Exp Dermatol 1987; 12:8-11.

6. Ramsay B, O'Reagan M. A survey of the social and psychological effects of psoriasis. Br J Dermatol 1988; 118:195-201.

7. Finlay AY, Coles EC. The effect of severe psoriasis on the quality of life of 369 patients. Br J Dermatol 1995 ; 132:236-244.

8. Jobling RG. Psoriasis-a preliminary questionnaire study of sufferers' subjective experience. Clin Exp Dermatol 1976; 1:233-236.

9. Roenigk RK, Roenigk Jr HH. Sex differences in the psychological effects of psoriasis. Cutis 1978; 21:529-533.

10. Gupta MA, Gupta AK. The Psoriasis Life Stress Inventory: a preliminary index of psoriasis-related stress. Acta Derm Venereol (Stockh) 1995; 75(3):240-243.

\section{Vulval Schistosomiasis}

Vulval schistosomiasis is being discovered with increasing frequency in the United Kingdom, especially in visitors returning from the African continent. It is usually associated with heavy $S$. haematobium infections and occasionally, $S$. mansoni infection. S. haematobium is endemic in Africa, Egypt and the Middle East. Infection occurs after swimming in infested lakes or rivers, and symptoms may not appear until many months after exposure to the parasite, as illustrated in this case.

The presentation in this patient was unusual as vulval schistosomiasis is usually asymptomatic. Clinically the granulomas most frequently appear as warty growths similar to condyloma acuminata, and are often misdiagnosed as 'vulval warts.' Other modes of presentation include 'fibromas,' vitiligo and, rarely, ulcers. Vulval disease is frequently associated with extensive infection of the urinary bladder, but this does not appear to have been the case in the patient reported here; she had no dysuria or haematuria, and few ova were present in the urine. From Desmond N, Hanna N. Coker RJ, et al. Schistosomiasis: an unusual cause of pruritus vulvae. J Eur Acad Dermatol Venereol 1994; 3:207. 
This document is a scanned copy of a printed document. No warranty is given about the accuracy of the copy. Users should refer to the original published version of the material. 